\title{
Features of Summer and Winter Precipitation in the Northern Part of the Black Sea Region: Two Model Case Studies
}

\author{
V. V. Efimov ${ }^{凶}$, A. E. Anisimov, O. I. Komarovskaya \\ Marine Hydrophysical Institute, Russian Academy of Sciences, Sevastopol, Russian Federation \\ 凶vefim38@mail.ru
}

Purpose. The purpose of the study is to reproduce the evolution of clouds and precipitation and to evaluate the summer and winter precipitation features in the Black Sea region and Crimea using the WRF-ARW model.

Methods and Results. The results of numerical simulations of the summer and winter atmospheric precipitation in Crimea, and the corresponding comparative characteristics are presented. Based on the example of the convection case in July 2018, shown are the convective activity diurnal dynamics and its spatial features induced by the breeze circulation over Crimea. Moisture balance analysis was performed, and quantitative estimates of the summer precipitation formation mechanism are given. The case study of December 2018 precipitation caused by the cyclone and associated cold front passage highlights the feature of the winter precipitation formation mechanism that is driven by moisture advection. The formation of intense winter and summer precipitation in the Crimean Mountains was also considered.

Conclusions. The characteristic feature of summer precipitation is its diurnal periodicity and internal moisture cycle. The impact of breezes leads to the localization of convective clouds and precipitation in the central regions of the peninsula. The winter precipitation-forming cloudiness in Crimea consists predominantly of stratiform clouds; the precipitation patterns are conditioned by the large-scale circulation: the external moisture cycle is of a decisive character in winter. The high-altitude mountain areas are the zones of maximum precipitation in both seasons; they play an important role in the total moisture balance in Crimea.

Keywords: $W R F$, precipitation, influence of breeze circulation, convective activity, moisture content, advective transport, summer and winter precipitation in mountains

Acknowledgements: the study was carried out within the framework of research project No. 20-45920017 "Quantitative estimates of precipitation in Southwestern Crimea and Sevastopol based on numerical modeling and radar observations" (financially supported by RFBR and the Sevastopol municipality) and state task No. 0827-2021-0002 "Fundamental studies of the interaction processes in the ocean-atmosphere system conditioning the regional spatial-temporal variability of natural environment and climate".

For citation: Efimov, V.V., Anisimov, A.E. and Komarovskaya, O.I., 2021. Features of Summer and Winter Precipitation in the Northern Part of the Black Sea Region: Two Model Case Studies. Physical Oceanography, [e-journal] 28(6), pp. 677-690. doi:10.22449/1573-160X-2021-6-677-690

DOI: $10.22449 / 1573-160 \mathrm{X}-2021-6-677-690$

(C) 2021, V. V. Efimov, A. E. Anisimov, O. I. Komarovskaya

(C) 2021, Physical Oceanography

\section{Introduction}

The northern part of the Black Sea region is an area with a temperate climate and relatively low annual precipitation. So, according to the measurements carried out in the central part of the Crimean Peninsula at the weather station in Simferopol, the annual precipitation amounts to $\sim 500 \mathrm{~mm}$. The climate of most of Crimea territory is semi-arid steppe. It is also characterized by significant spatial variability due to its proximity to the sea and the presence of mountains [1-3]. In coastal areas, the precipitation formation is affected by the effects of breeze 
circulation, leading, in particular, to a noticeable decrease in precipitation in the warm season. For example, summer July precipitation in Sevastopol averages $27 \mathrm{~mm}$, while in Simferopol - $43 \mathrm{~mm}$, which is almost 2 times higher.

The physical mechanism of the Crimean Mountains ridge impact on the formation of a subtropical climate in a narrow coastal strip of the Southern Coast of Crimea is described in [4]. High-mountain regions, where breezes, foehns and other types of mountain winds are formed, which also determine the submesoscale features of atmospheric circulation and local precipitation heterogeneity [5], require separate consideration.

Statistical characteristics of the precipitation regime in Crimea, such as the frequency of extreme precipitation, the frequency of dry and humid periods, as well as the climatic trends of these values, are clearly insufficiently studied to date * [6]. First of all, this is due to the scarcity and incompleteness of precipitation measurements in Crimea. Novel satellite datasets that are currently being formed, in combination with the capabilities of modern numerical models for regional meteorological reanalysis [7], can significantly expand the required precipitation database.

From a practical point of view, the most important feature is the frequency of extreme precipitation, which are determined by the value of the 99th percentile of the distribution density function * [6] and cause significant economic consequences (flash floods, destruction of bridges, etc.). It is important to note a particular feature of extreme precipitation in Crimea: it occurs, as a rule, in the summer-autumn warm period of the year.

Indeed, the intensity of precipitation in June and December - the months of maximum precipitation within the annual cycle - varies considerably. Thus, rather rough estimates of the intensity (defined as the amount of precipitation divided by its duration) according to measurements at the Simferopol weather station for the period of 2005-2020 are $1 \mathrm{~mm} / \mathrm{h}$ in June, and $0.49 \mathrm{~mm} / \mathrm{h}$ in December, which is significantly less [7].

In the warm season from May to September, convective precipitation is typical in Crimea, with a maximum frequency of occurrence in June. To date, the physical mechanisms of the development of convective clouds and the microphysical processes of the formation of liquid and solid phase components of cloudiness and precipitation have been well studied. The features of the development of convective structures in certain regions of the globe, such as tropical hurricanes, mesoscale subtropical hurricanes or polar cyclones are also well known.

Note that some important features of the convective clouds' formation depend on regional characteristics - topography, the presence of mountains, proximity to large water basins, etc. In this regard, the Black Sea basin, where the seasonal variation of convective cloudiness over the sea is controlled by its thermal regime, and over the Crimea where it is determined by the proximity of the sea, is of undoubted interest. In addition, the presence of fairly high mountains determines the mesoscale heterogeneity of cloudiness and precipitation over the southern part of the peninsula. It is also important to note that these features are highly seasonal.

*Zolina $O$. G. Statistical modeling of extreme precipitation and the regional atmospheric moisture cycle: Abstract of Dr.Sci. (Phys.-Math.) thesis, M., 2018, 57 p. 
In order to reproduce the processes of cloudiness and precipitation development using $W R F-A R W$ model, as well as to highlight the precipitation features for the Black Sea region and Crimea in the summer and winter seasons, we will consider the results of numerical modeling of two typical cases of heavy precipitation, July 13-15 and December 11-12, 2018. It will be shown that whether the precipitation amounts during these two cases were comparable, the nature and physical features of its formation differed significantly.

\section{Numerical model}

We used the well-known numerical model of atmospheric circulation WRF$A R W$ version 4.0.1 [8], configured for the calculation in the Black Sea region with the required settings of the physical processes parameterizations (first of all, the parameterization of the convective atmospheric boundary layer (ABL)). In Fig. 1 the location of domains with 900 and $2700 \mathrm{~m}$ resolution is shown. The model is rather well-known; therefore, we only note the main settings.

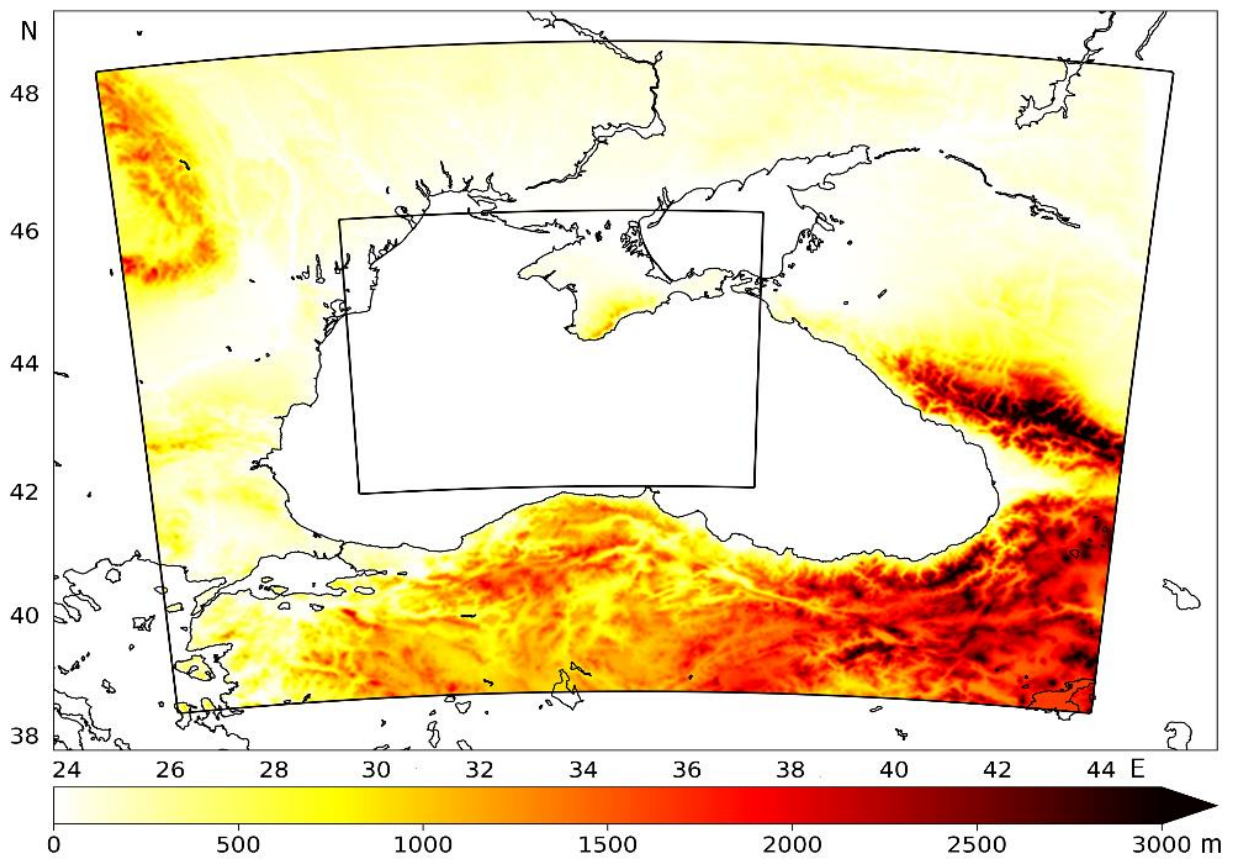

F i g. 1. $W R F$ model domains and terrain elevation (m)

39 vertical hybrid levels the with the increased resolution in the planetary boundary layer were set. The parameterization schemes of the subgrid processes were chosen in accordance with the NCAR convection-permitting suite configuration. This WRF configuration has been actively tested and verified during many research and applied experiments [9, 10], it is used operationally for numerical weather prediction in the continental United States [11]. First of all, the configuration is intended for calculations in the convective-resolving mode, when the model spatial step is less than 4-5 km and the convection 
parameterization scheme is not used, which corresponds to our problem. The use of the input data of Integrated Forecasting System (IFS) model [12] from the operational analysis fields of the European Center for Medium-Range Weather Forecasts $(E C M W F)$ with $9 \times 9 \mathrm{~km}$ resolution, which were updated every $6 \mathrm{~h}$ allowed to run WRF simulations in a convective-resolving mode starting from the first domain. After the model adaptation to the given initial conditions, the development of atmospheric processes in all domains was determined only by periodically updated input data, specifying the boundary conditions on the external domain.

The only difference between the chosen configuration and NCAR convectionpermitting suite is the choice of a parameterization scheme for cloud microphysical processes and precipitation formation. During the preliminary experiments, it was determined that the default Thompson scheme [13] can significantly overestimate the mass of hydrometeors (and, accordingly, the radar reflectivity), while the precipitation is underestimated (which was also noted in other works, for example, in [14]). The best results were obtained using dobule-moment Milbrandt parameterization scheme $[15,16]$, where both the total concentration and the number of hydrometeor particles are prognostic variables. Thompson scheme is partially double-moment. In order to calculate the transfer of short-wave and long-wave radiation, the Rapid Radiative Transfer Model for GCMs (RRTMG) scheme was used [17], for the parameterization of turbulent mixing processes in the boundary layer Mellor - Yamada - Janjic scheme [18], for reproducing the processes of heat and moisture exchange in the upper soil layer - Noah LSM scheme [19].

\section{Summer precipitation characteristics}

A case of precipitation on July 13-15, 2018, when sufficiently heavy rains (up to $50 \mathrm{~mm}$ per day) were observed over most of Crimea, was simulated. The synoptic situation over Crimea was characterized by a low-gradient pressure field, mainly northwesterly winds with a velocity of up to $10 \mathrm{~m} / \mathrm{s}$, and a daytime temperature of $30-32{ }^{\circ} \mathrm{C}$. In Fig. 2 the distribution of daily precipitation amounts over Crimea for July 13, 2018 according to the model results and observations at 21 meteorological stations is given.

A characteristic feature of the precipitation distribution is its concentration in the central region of Crimea. No precipitation was observed in the coastal northwestern and southwestern parts of the peninsula at a distance of up to $\sim 50 \mathrm{~km}$ from the coast. The main cause for this distribution is breeze circulation, which prevented the occurrence of convective clouds in this zone, where relatively cold air from the sea has spread [5]. This feature is typical for all cases of warm-season convective precipitation in Crimea, although in this example there is also some impact from the background northwesterly wind of moderate velocity in the morning hours (up to $5 \mathrm{~m} / \mathrm{s}$ ). The reconstructed precipitation is in good agreement with the one measured at meteorological stations: it can be seen that, just as according to the simulation results, the maximum precipitation was recorded at stations in the northern steppe part of Crimea, as well as in the mountains. The area of maximum precipitation is not reflected in the observational data due to the absence of weather stations in this sparsely populated part of the peninsula. 


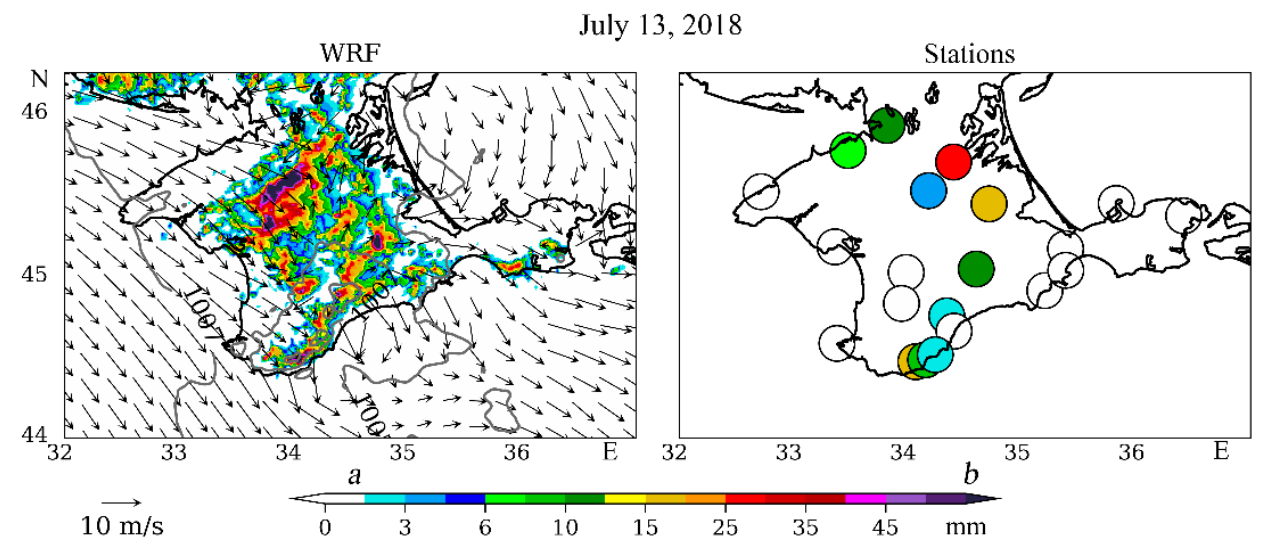

F i g. 2. Accumulated precipitation over Crimea at 15:00 on July 13, 2018 (color), $10 \mathrm{~m}$ wind velocity vectors (arrows), sea level pressure field (grey isolines) based on the WRF data $(a)$ and precipitation daily totals based on the weather stations data $(b)$

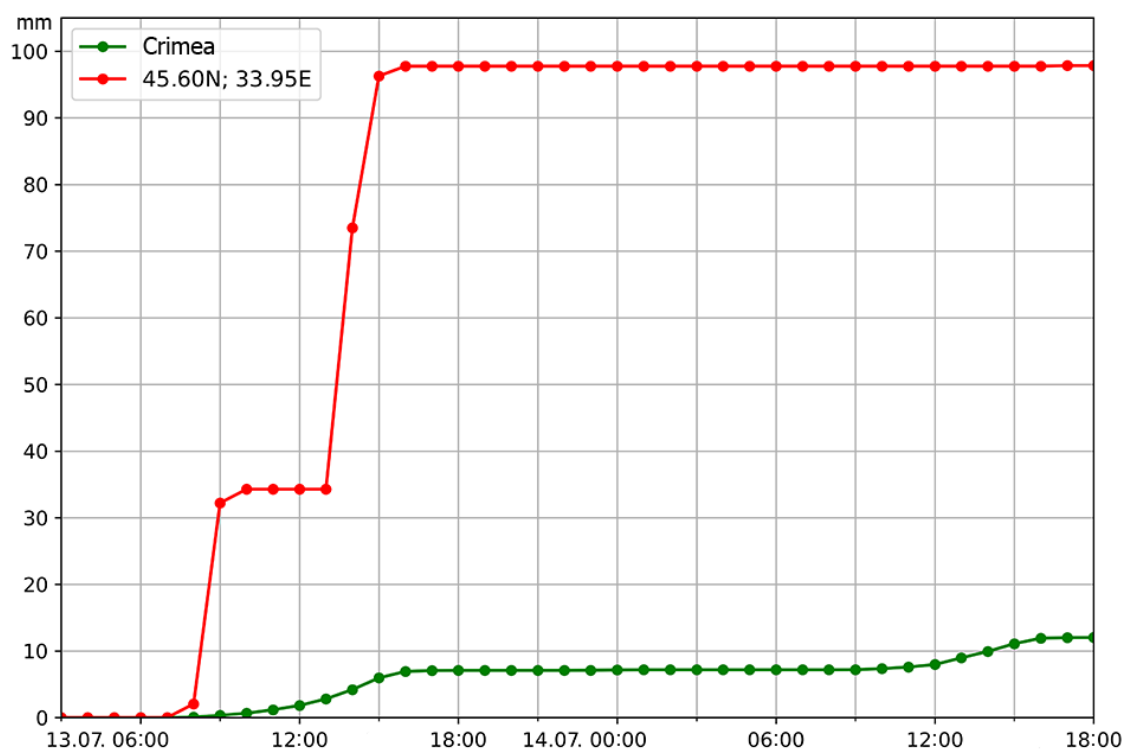

F i g. 3. Time series of the accumulated precipitation at $45.6^{\circ} \mathrm{N}, 33.95{ }^{\circ} \mathrm{E}$ and those averaged for the entire territory of Crimea for July, 13 (06:00) - July, 14, 2018 (12:00)

Daily rainfall variation is shown in Fig. 3. As can be seen, the precipitation variation at a particular point characterizes the relatively short duration of this rainfall event, although it was quite strong. At the same time, area-averaged precipitation also occurred in relatively short intervals, from 14:00 to 17:00 LT, which corresponds to the period of the maximum ABL heating and maximum development of deep convective clouds.

We also note that the amount of precipitation was small in the areas closer to the coast ( 10-20 mm), reaching 40-100 mm only in the central part (Fig. 3). Here, the structure of cloudiness and precipitation had all the features of verticallydeveloped cumulonimbus convective clouds. An example of the vertical structure PHYSICAL OCEANOGRAPHY VOL. 28 ISS. 6 (2021) 
of such a cloud, developed at a point of $45.6^{\circ} \mathrm{N}$ and $33.95^{\circ} \mathrm{E}$ are shown in Fig. 4. The $\{\mathrm{u}, \mathrm{w}\}$ vectors, where $\mathrm{u}$ is a zonal velocity and $\mathrm{w}$ is a vertical velocity are also shown. The relative humidity area of $\sim 100 \%$, corresponding to the area of the convective cloud, reached altitudes of $\sim 10 \mathrm{~km}$. In the central part of the cloud, the velocities of the ascending movement reached $10 \mathrm{~m} / \mathrm{s}$. In the lower part, in the region of $33.95-34.1^{\circ} \mathrm{E}$ at heights up to $1000 \mathrm{~m}$ and relative humidity of 50 $60 \%$, an area of subsidence develops due to the effects of air entrainment by raindrops.

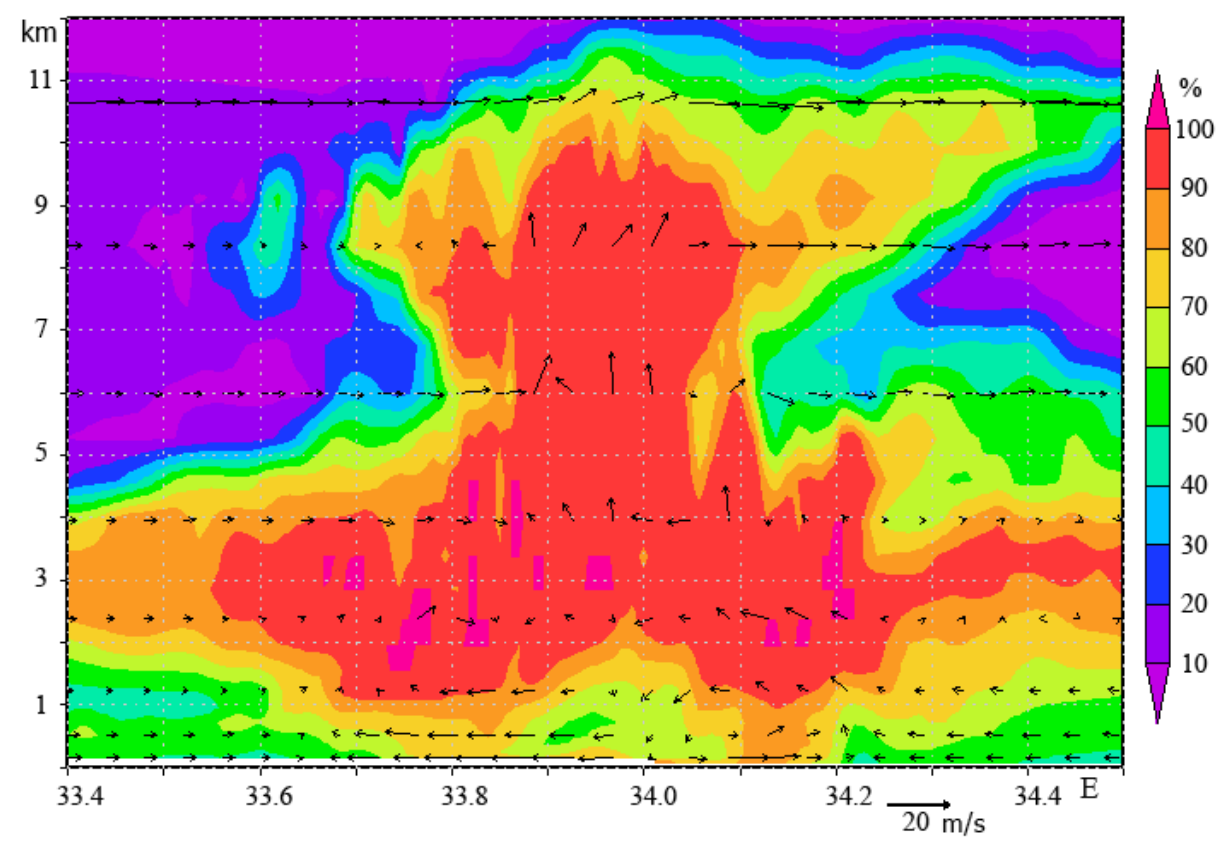

F i g. 4. Relative humidity vertical structure at the zonal cross-section at $45.6^{\circ} \mathrm{N}$. Arrows show the wind velocity vectors with the $\{\mathrm{u}, \mathrm{w}\}$ components, where $\mathrm{u}$ is the zonal component and $\mathrm{w}$ is the vertical one

It is interesting to evaluate the source of moisture in the considered episode of heavy rainfall. For this purpose, we return to Fig. 3 and consider Fig. 5, which shows the vertical profiles of the total moisture content - the particle concentrations $\left(\mathrm{g} / \mathrm{m}^{3}\right.$ of moist air) for all hydrometeors (cloud droplets (small), raindrops (large), snow, ice, hail, graupel) for three points in time: the first (14:00, July 13) corresponds to the midtime of a heavy rain, the second one (15:00) is closer to its end, and the third one (16:00) corresponds to the time after the rainfall event has finished, i.e. immediately after the rain cloud has passed. A characteristic feature is a dramatic decrease of the moisture content in the air, covering the entire layers up to $12 \mathrm{~km}$ (i.e. the area of a cumulus convective cloud), during the second half of the rainfall, up to almost complete exhaustion at the final stage. The estimate of the total loss of water mass per unit area for 13:00-14:00 time interval is $\sim 15 \mathrm{~mm}$, which is quite close to the simulated amount of precipitation at this point (Fig. 3). Of course, this is only a rough estimate of the correspondence between the moisture accumulated in the atmospheric cloud and the precipitated 
convective rain amount. It is necessary to note a lot of uncertainties, and especially rather coarse spatial and temporal resolution of the model. Note that the averaged daily precipitation amount over the entire area of Crimea on that day was $\sim 8 \mathrm{~mm}$.

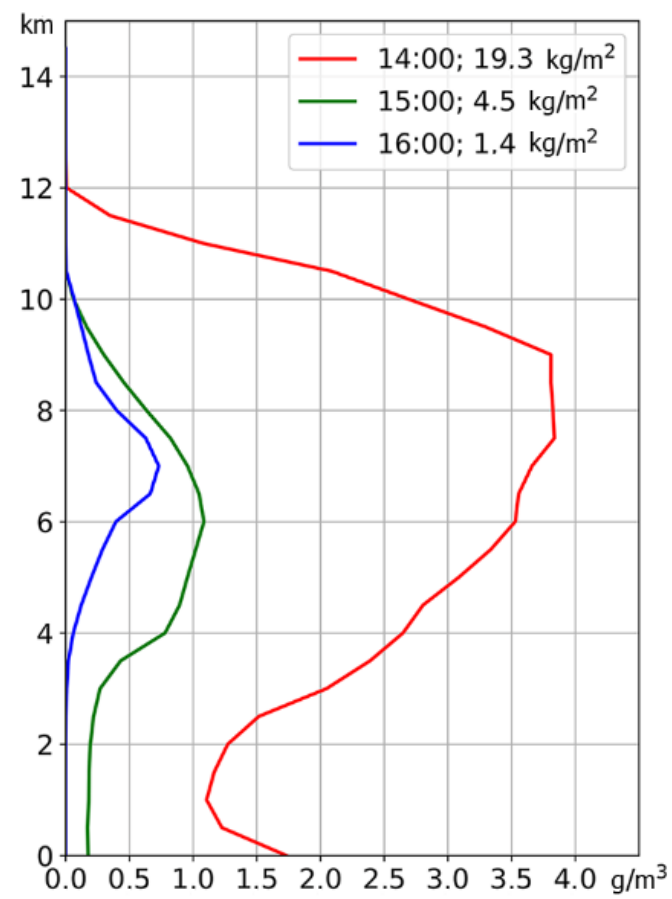

F i g. 5. Vertical profiles of the total moisture content for three time steps on July 13, 2018

Thus, numerical modeling provides rather good reconstruction of the formation of cloudiness and summer rainfall over Crimea, while the characteristic features of the spatial distribution of precipitation controlled by breeze circulation that, in its turn, depends on the proximity to the sea, coastline and orography, are clearly visible [5]. In summer, internal moisture cycle prevails, at which the source of moisture in the clouds and, accordingly, the source of rainwater is local evaporation from the surface of Crimea.

\section{Precipitation in the cold period of the year}

In contrast to summer, in winter the typical type of cloudiness over Crimea is stratiform. Convective cloudiness is a rather rare phenomenon, which, although it occurs during the cold air intrusions, has the form of organized cellular or roll convection, limited by the lower atmosphere to the heights of $~ 1-2 \mathrm{~km} \mathrm{[20]} \mathrm{and}$ not associated with the precipitation. Heavy rains falling from stratiform clouds are the main inflow sources of the water balance of the Crimean Peninsula.

In Fig. 6 the surface isobars, wind velocity vectors at $10 \mathrm{~m}$ height and rainfall distribution from $\operatorname{WRF}(a)$, and daily precipitation totals at the stations $(b)$ for one of such cases (December 11, 2018), are given. This is a typical example of precipitation associated with the cold front at the northwestern periphery of 
the cyclone centered southward of Crimea. Satellite images of cloud cover show a continuous cloud area over the entire Crimean-Black Sea region. The values of the reconstructed precipitation are in good agreement with the measured ones: 30 $40 \mathrm{~mm}$ of precipitation was observed over most of the peninsula. The maximum (up to $50 \mathrm{~mm}$ ) is noted in the steppe area. In the easternmost and westernmost parts of Crimea a reduced amount of precipitation (up to $20 \mathrm{~mm}$ ) was both observed and simulated by the model.

December 11, 2018

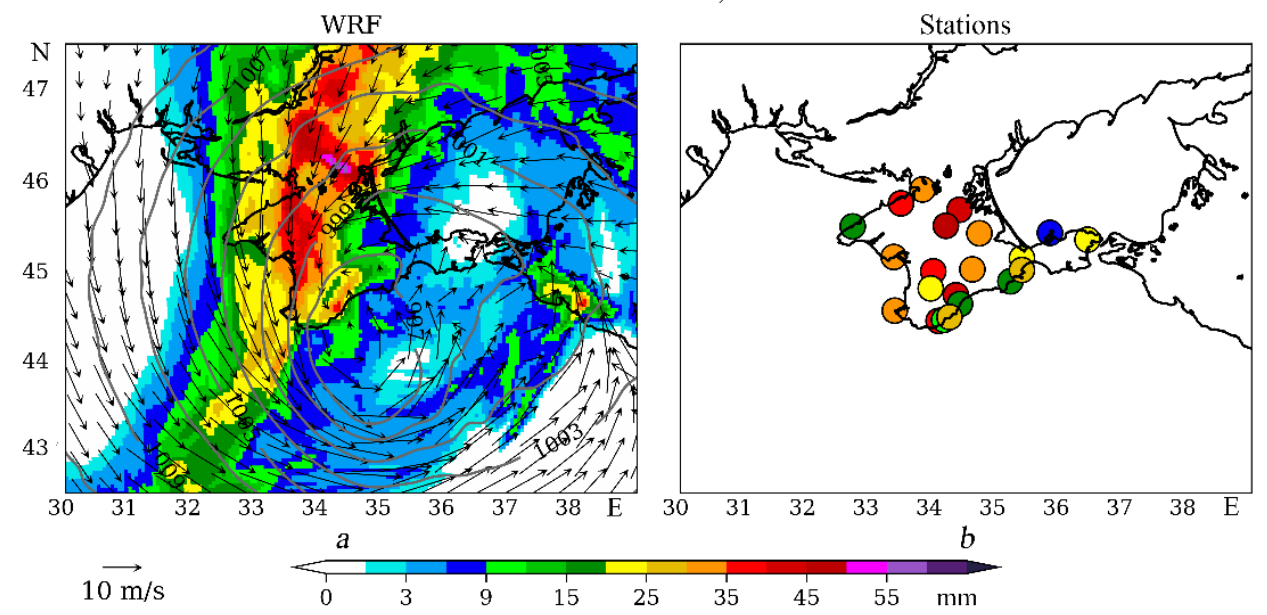

F i g. 6. Accumulated precipitation over Crimea at 13:00 on December 11, 2018 (color), wind velocity vectors at the $10 \mathrm{~m}$ height (arrows), sea level pressure field (grey isolines) based on the WRF data $(a)$ and precipitation daily totals based on the weather stations data $(b)$

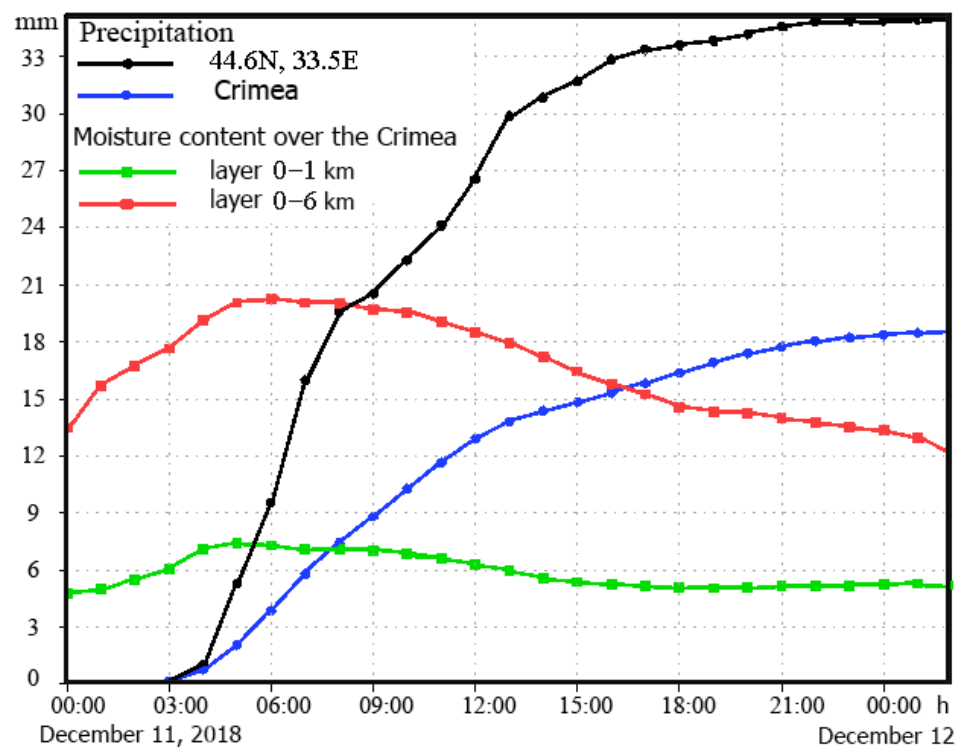

F i g. 7. Time series of the accumulated precipitation at $44.6^{\circ} \mathrm{N}, 33.5^{\circ} \mathrm{E}$ and those averaged for the entire territory of Crimea; moisture content also averaged for the entire territory of Crimea over the atmospheric layers $0-1$ and $0-6 \mathrm{~km}$ 
In Fig. 7 temporal variations of precipitation are given. Unfortunately, the only measurements available at the Sevastopol weather station were the 12-hour precipitation accumulations. Nevertheless, in general, the observations are generally in good agreement with simulations with an average bias of 3-6 mm. The amount of precipitation in the December case was significantly higher than on the previously considered summer case, which is not surprising, taking into account that this heavy winter rain lasted during almost the entire day.

Returning to the question on the moisture source for the rainwater and the type of moisture cycle during the winter period, we consider the temporal variations of moisture content in the atmosphere in the $0-6 \mathrm{~km}$ layer and in its lower part $(\sim 0-1 \mathrm{~km})$ shown in Fig. 7. Some relationship between moisture content and precipitation, expressed as a tendency for moisture content to decrease as it rains, can be seen. However, the decrease in moisture content itself is generally insignificant in magnitude. A simple estimate of the decrease in moisture content in 6-kilometer layer by $\sim 3 \cdot 10^{-4} \mathrm{~kg}_{\mathrm{w}} / \mathrm{kg}_{\mathrm{a}}$ (where $\mathrm{kg}_{\mathrm{w}}$ is the weight of water vapor, $\mathrm{kg}_{\mathrm{a}}$ is the weight of moist air) corresponds to $10 \mathrm{~mm}$ of precipitation liquid, which is $\sim 2.5$ times less than the amount of precipitation actually simulated at this point for a time period of $\sim 9$ hours.

Of course, such a conclusion can only be of a qualitative nature. In contrast to the summer period, when the moisture content profiles compared differed in time by 1 hour, and the near-surface wind velocities under the convective cloud were low, the considered winter stratiform clouds developed in the vicinity of the cyclone with wind velocities of $15-20 \mathrm{~m} / \mathrm{s}$. Therefore, the advective transport of moisture in the clouds played a decisive role in the formation of precipitation over particular areas. Thus, we can only indicate that in the considered case of a winter heavy rainfall, the external moisture cycle was decisive: the moisture balance on the spatial scales of the size of Crimea was determined by moisture brought by stratiform clouds from the neighboring regions of the Black Sea basin.

\section{Precipitation in the high mountains area}

A ridge of rather high mountains controls the climate of the Southern Coast of Crimea [4]. The precipitation in the mountains, enhanced by the orographic effect, cause an increased surface and subsurface runoff in the foothill and steppe regions. Thus, the mountains have an impact on the water balance of the entire peninsula. The issues of the formation of the water balance require special studies supplemented by the complex high-resolution numerical modeling of the regional water balance, including the estimates of precipitation, evaporation, and the runoff components. They are beyond the scope of this paper. At the same time, due to the scarcity and fragmented character of the observational datasets, it is of interest to present the simulated precipitation in the high mountains area for two considered examples.

In Fig. 8 the precipitation fields for the summer and winter periods, respectively, are shown. In the first approximation, their spatial distribution is fairly close, with precipitation amounts in the high mountains reaching 90$110 \mathrm{~mm}$. The maximum precipitation is concentrated in the regions of the four 
highest mountains with 1000-1200 m heights. A simple physical mechanism the rise of humid air to the top of the mountains in summer and condensation of water vapor in the area above the peak - explains the rain formation. For the winter case, the vertical structure of the airflow over the mountain is shown in Fig. 9. The raindrop concentration values $\left(\mathrm{kg}_{\mathrm{w}} / \mathrm{kg}_{\mathrm{a}}\right)$ and the $\{\mathrm{v}, 5 \mathrm{w}\}$ velocity vectors are given. As a result of the blocking of the approaching cold air by the mountain, the air rises over the mountain peak to the heights of $3.5-4.5 \mathrm{~km}$, and the condensed drops of water in the area of these heights precipitate in the form of rain.

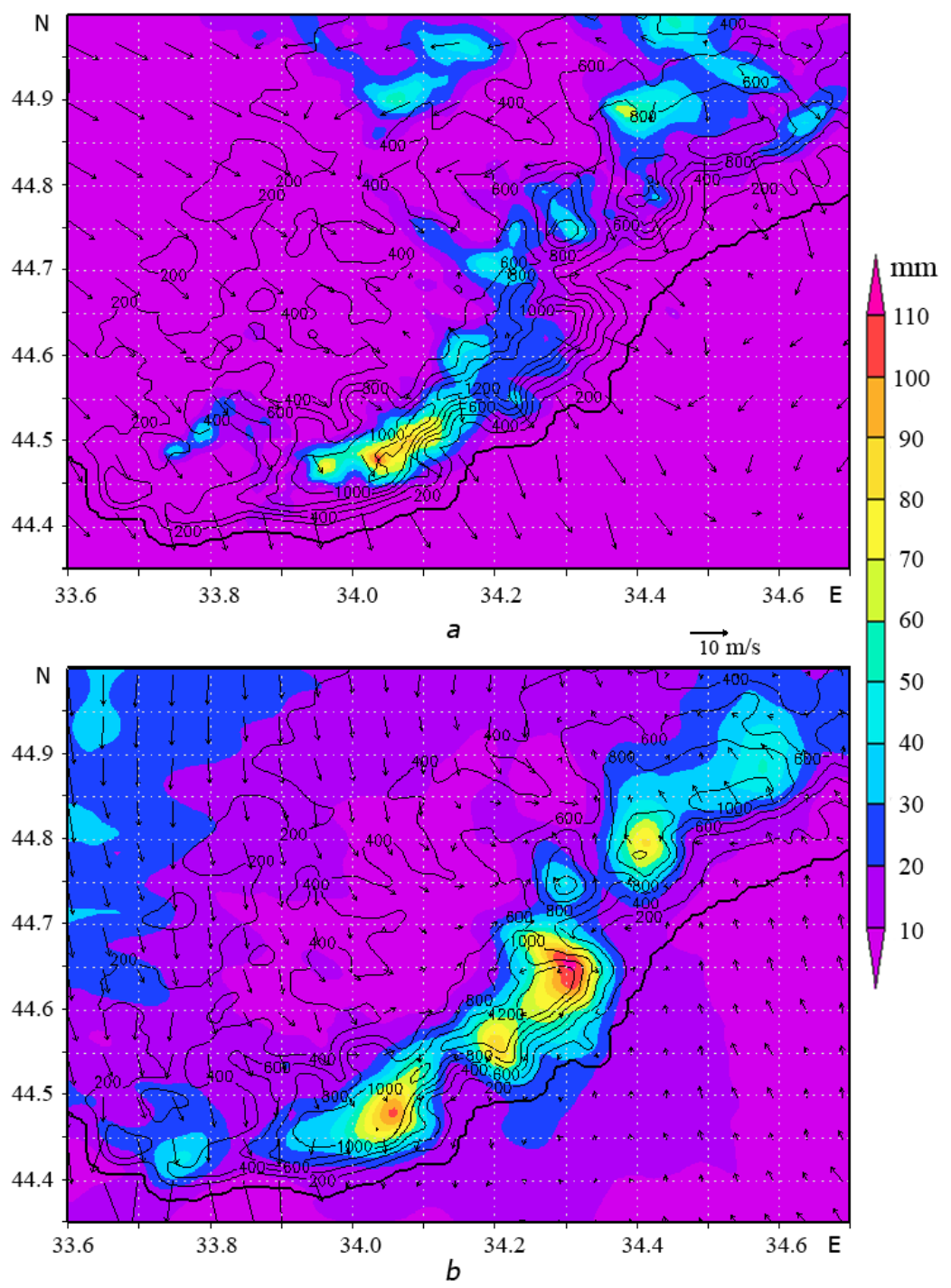

F i g. 8. Accumulated precipitation over the southern part of Crimea at 15:00 on July 14, 2018 (a) and at 13:00 on December 11, 2018 (b) (arrows show the $10 \mathrm{~m}$ wind velocity, isolines show the terrain elevation) 
The direction of the background wind plays a significant role for such rains. The flow around mountains with a stably stratified winter air flow can be quite complex and the localization of rainfall in the ridge area depends on the wind direction relative to the ridge line. This can explain a small but noticeable difference in the location of the maximum precipitation relative to the mountain peaks in the considered cases (Fig. 8).

In summer, precipitation maxima are generally shifted to the northern slope of the mountains, while in winter they are closer to the southern slope (except for AiPetri). The explanation for this is probably related to the wind direction in the lower part of the atmosphere. In summer, the southern wind rises the air and causes rain on the southern slope of the mountains. In winter, the wind is blocked by the mountain, and the low wind velocity above the peak leads to rainfall formation on the mountain top.

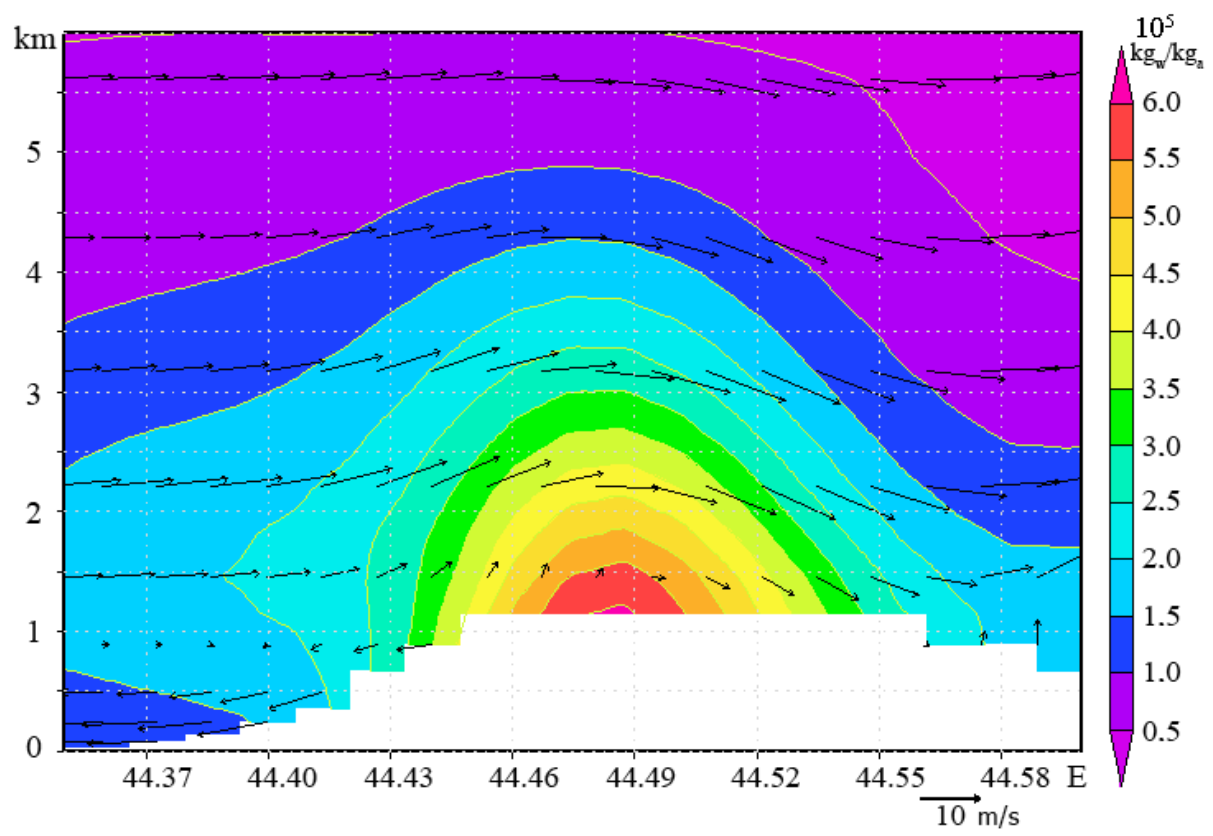

F i g. 9. Raindrop concentration vertical profile at the meridional cross-section at $34.05^{\circ}$ E. Arrows show the wind velocity vectors with the $\{\mathrm{v}, 5 \mathrm{w}\}$ components, where $\mathrm{v}$ is the zonal component and $\mathrm{w}$ is the vertical one

Thus, the presence of high mountains determines the areas of long and heavy precipitation in summer and winter. In this regard, they play an important role in the total moisture balance of Crimea, considering the proximity to the settlements of the Southern Coast. It should be taken into account that the storage reservoirs are located to the south from the high-altitude part of the Crimean Mountains, and, as can be seen from the distribution of summer (Fig. 2) and winter (Fig. 6) rains, the precipitation is generally low in the southern foothills (at least in the considered examples). 


\section{Conclusion}

Numerical modeling of two cases of cloudiness development and precipitation formation in summer and winter seasons in the Black Sea region and Crimea was carried out with a sufficiently high spatial resolution $(900 \mathrm{~m})$. For the successful simulation of cloudiness and convective-type precipitation in summer (July 2018), the choice of the convective-resolving spatial step was especially important.

It is known that a characteristic feature of summer precipitation is its daily periodicity. For Crimea, it significantly depends on the breeze circulation. It is shown that the effect of breezes leads to the localization of convective cloudiness and precipitation in the central regions of the peninsula. As a result, only scattered clouds are usually seen in the coastal areas, whereas heavy precipitation is observed in the central regions of Crimea. In this case, the source of moisture is the internal water cycle, i.e. the moisture locally evaporated from the territory of Crimea. Such a simple scheme can be disrupted by the presence of a strong external background (synoptic) circulation.

Winter cloudiness forming the precipitation in Crimea (mainly nimbostratus clouds) is considered in the second model example (December 2018). It is demonstrated that the moisture source for heavy rains in this case is the advection of water vapor from neighboring areas due to high airflow rates.

The high Crimean Mountains are of great importance in the localization of precipitation. The region of the highest mountains is the zone of maximum precipitation in both periods of the year. The role of the mountains is noted as the main source of moisture supply to the southern foothill regions of Crimea, in which direct precipitation, according to the results of two modeling cases, turned out to be insignificant.

\section{REFERENCES}

1. Logvinov, K.T. and Barabash, M.B. eds., 1982. Climate and dangerous hydrometeorological phenomena of Crimea. Leningrad: Gidrometeoizdat, 117 p. (in Russian).

2. Ved, I.P., 2000. Climatological atlas of Crimea. Simferopol: Tavriya-Plus, 120 p. (in Russian).

3. Anisimov, A.E., Efimov, V.V. and Lvova, M.V., 2021. Evaluation of GPM IMERG products and estimation of warm-season precipitation in Crimea. Physical Oceanography, [e-journal] 28(4), pp. 445-459. doi:10.22449/1573-160X-2021-4-445-459

4. Efimov, V.V. and Yarovaya, D.A. 2014. Numerical Simulation of Air Convection in the Atmosphere During the Invasion of Cold Air over the Black Sea. Izv. Atm. and Ocean. Physics, 50(6), pp. 610-620. DOI: 10.1134/S0001433814060073

5. Efimov, V.V. and Komarovskaya, O.I. 2019. Mountain Effects on Climate on the Southern Coast of Crimea. Russian Meteorology and Hydrology, (9), pp. 86-94. eLIBRARY ID: 40834989 (in Russian)

6. Zolina, O.G. and Bulygina, O.N., 2016. Modern climatic variability of extreme precipitation characteristics in Russia. Fundamental'naya i prikladnaya klimatologiya, 1, pp.84-103. https://doi.org/10.21513/2410-8758-2016-1-84-103 (in Russian).

7. Efimov, V.V. 2017. Numerical Simulation of Breeze Circulation over the Crimean Peninsula. Izv. Atm. and Ocean. Physics, 53(1), pp. 84-94. DOI: 10.1134/S0001433817010042 
8. Skamarock, W.C., Klemp, J. B., Dudhia J., Gill, D.O., Liu, Z., Berner, J and Huang, X.-yu., 2019. A description of the advanced research WRF model version 4. National Center for Atmospheric Research: Boulder, CO, USA, 145 p. doi:10.5065/1dfh-6p97

9. Clark, A.J., Kain, J.S., Coniglio, M., et al. 2012. An Overview of the 2010 Hazardous Weather Testbed Experimental Forecast Program Spring Experiment. Bull. Amer. Meteor. Soc., (93), pp. 55-74. doi:10.1175/BAMS-D-11-00040.1

10. Schwartz, C. S., Kain J.S., et al. 2010. Toward improved convection-allowing ensembles: Model physics sensitivity and optimizing probabilistic guidance with small ensemble membership. Wea. Forecasting, (25), pp. 263-280. doi:10.1175/2009WAF2222267.1

11. Schwartz, C.S., Romine, G.S., et al. 2015. NCAR's experimental real-time convectionallowing ensemble prediction system. Wea. Forecasting, (30), pp. 1645-1654. (DOI: 10.1175/WAF-D-15-0103.1).

12. Ehard, B., Malardel, S., Dörnbrack A., et al. 2018. Comparing ECMWF high-resolution analyses with lidar temperature measurements in the middle atmosphere. Quart. J. Roy. Meteorol. Soc., 144(712), pp. 633-640. https://elib.dlr.de/115969/

13. Thompson, G., Field, P.R., Rasmussen, R.M. and Hall, W.D. 2008. Explicit forecasts of winter precipitation using an improved bulk microphysics scheme. Part II: Implementation of a new snow parameterization. Mon. Wea. Rev., (136), pp. 5095-5115.

https://doi.org/10.1175/2008MWR2387.1

14. Fan, J., Han, B., Varble A., et al. 2017. Cloud-resolving model intercomparison of an MC3E squall line case: Part I - Convective updrafts. J. Geophys. Research: Atmospheres, 122(17), pp. 9351-9378. DOI: $10.1002 / 2017 \mathrm{jd} 026622$

15. Milbrandt, J.A. and Yau, M.K., 2005. A multimoment bulk microphysics parameterization. Part I: Analysis of the role of the spectral shape parameter. J. Atmos. Sci., (62), pp. 30513064. DOI:10.1175/JAS3534.1

16. Milbrandt, J.A. and Yau, M.K., 2005. A multimoment bulk microphysics parameterization. Part II: A proposed three-moment closure and scheme description. J. Atmos. Sci., (62), pp. 3065-3081. DOI:10.1175/JAS3535.1

17. Iacono, M.J., Delamere, J.S., Mlawer, E.J., et al. 2008. Radiative forcing by long-lived greenhouse gases: Calculations with the AER radiative transfer models. J. Geophys. Research, 113, D13103. https://doi.org/10.1029/2008JD009944

18. Janjić, Z. I. 1994. The step-mountain Eta coordinate model: Further developments of the convection, viscous sublayer and turbulence closure schemes. Mon. Weather Rev., 122(5), pp. 927-945. https://doi.org/10.1175/1520-0493(1994)122<0927:TSMECM>2.0.CO;2

19. Chen, F., Janjic, Z. and Mitchell, K.E. 1997. Impact of atmospheric surface-layer parameterizations in the new land-surface scheme of the NCEP mesoscale Eta model. Boundary Layer Meteorol., 85, pp. 391-421. doi:10.1023/A:1000531001463.

20. Zacz, V.I., Luk yanenko, O.Ya. and Yacevich, G.E. 1966. Hydrometeorological regime of the southern coast of Crimea. Leningrad: Gidrometeoizdat, 120 p. (in Russian) https://search.rsl.ru/ru/record/01006193330

About the authors:

Vladimir V. Efimov, Head of Atmosphere and Ocean Interaction Department, FSBSI FRC MHI (2, Kapitanskaya str., Sevastopol, 299011, Russian Federation), Dr.Sci. (Phys.-Math.), Professor, ORCID ID: 0000-0002-4262-9902, ResearcherID: P-2063-2017, Scopus Author ID: 7202138991, vefim38@mhi-ras.ru 
Anatolii E. Anisimov, Senior Research Scientist, Atmosphere and Ocean Interaction Department, FSBSI FRC MHI (2, Kapitanskaya str., Sevastopol, 299011, Russian Federation), Ph.D. (Phys.-Math.), ORCID ID: 0000-0002-5530-5608, ResearcherID: ABA-1705-2020, Scopus Author ID: 42561044300, anatolii.anisimov@mhi-ras.ru

Olga I. Komarovskaya, Research Scientist, Atmosphere and Ocean Interaction Department, FSBSI FRC MHI (2, Kapitanskaya str., Sevastopol, 299011, Russian Federation), ResearcherID: G-1814-2019, Scopus Author ID: 6504262996, komarovskaya@mhi-ras.ru

Contribution of the co-authors:

Vladimir E. Efimov - statement of the problem, interpretation of the results.

Anatolii E. Anisimov - analysis of the results.

Olga I. Komarovskaya - numerical modeling.

All the authors have read and approved the final manuscript.

The authors declare that they have no conflict of interest. 